\title{
ANALISIS LOYALITAS PELANGGAN DITINJAU DARI FAKTOR KEPERCAYAAN DAN KEPUASAN PELANGGAN PADA BENGKEL SEPEDA MOTOR AHASS 2192
}

\author{
Putra Chairy, SE,MM \\ Universitas Amir Hamzah \\ putrachairy@gmail.com
}

\begin{abstract}
Abstrak
Penelitian ini bertujuan untuk mengetahui "Pengaruh Kepercayaan dan Kepuasan Pelanggan Terhadap Loyalitas Pelanggan pada Bengkel Sepeda Motor AHASS 2192 Medan.Jenis penelitian ini adalah asosiatif. Populasi dalam penelitian ini adalah seluruh pelanggan pada Bengkel Sepeda Motor Ahass 2192 Medan sebanyak 150 pelanggan dengan menggunakan teknik rumus slovin, maka jumlah sampel dalam penelitian ini sebanyak 109 responden diambil dari sebagian populasi. Berdasarkan hasil uji t dapat dilihat bahwa thitung pada variabel kepercayaan dan kepuasan sebesar berpengaruh terhadap variabel loyalitas secara parsial.Berdasarkan hasil uji $\mathrm{F}$ maka menunjukan kepercayaan dan kepuasan secara serempak berpengaruh secara positif dan signifikan terhadap variabel loyalitas. Nilai Adjusted R Square yang diperoleh sebesar 0,451 atau $45,1 \%$. loyalitas dapat dijelaskan oleh kepercayaan dan kepuasan. Sisanya sebesar 54,9\% dipengaruhi oleh faktorfaktor lain yang tidak dijelaskan dalam penelitian ini.
\end{abstract}

Kata kunci: Kepercayaan, Kepuasan, Loyalitas

\section{PENDAHULUAN}

Salah satu faktor yang mempengaruhi dalam loyalitas pelanggan dalam penelitian ini adalah kepercayaan dan kepuasan pelanggan. Kepercayaan pelanggan pada merek di atas dikaitkan dengan kesediaan pelanggan menerima risiko dengan harapan pelanggan akan memperoleh nilai sesuai atau melebihi harapannya. Inti

Jurnal Insitusi Politeknik Ganesha Medan

Juripol, Volume 4 Nomor 1 Maret 2021 
yang membuat pelanggan percaya pada perusahaan atau merek tertentu adalah keterandalan janji yang disampaikan kepadapelanggan, janji tersebut mampu dilaksanakan dan semua personil perusahaan komitmen untuk memenuhi janji tersebut, perusahaan atau merek tertentu. Selain faktor kepercayaan, faktor kepuasan pelanggan juga menjadi salah satu faktor yang mempengaruhi loyalitas pelanggan. Kepuasan pelanggan adalah keluaran dari proses kinerja sebuah perusahaan yang dirasakan oleh seorang konsumen, dimana hasilnya sesuai dengan harapan konsumen tersebut (Pelanggan akan merasa puas apabila produk yang di belinya sesuai dengan kebutuhan, keinginan, serta harapan yang ingin dicapai oleh pelanggan tersebut.

Banyaknya jumlah bengkel AHASS di suatu daerah menimbulkan persaingan antara sesama bengkel AHASS yang lain. Dengan kata lain hal tersebut menjadi bahan pertimbangan paling utama bagi pelanggan sebelum datang untuk menggunakan jasa bengkel Sepeda Motor AHASS yang dipercayainya. Bengkel Sepeda Motor AHASS 2192juga merupakan perusahaan yang berfilosofi dalam hal mengutamakan Kepercayaan dan Kepuasan para pelanggannya.Berdasarkan survey terdahulu dan secara langsung ke lapangan yang dilakukan penulis terdapatlah fenomena masalah yang berhubungan dengan menurunnya loyalitas pelanggan dikarenakan tingkat kepercayaan menipis dan kurang puasnya pelanggan menggunakan jasa ini.Fenomena kepercayaan, di dalam persaingan jasa bengkel saat ini.Banyaknya terdapat persaingan yang terlihat dari banyaknya merek didalam industri bengkel saat ini. Banyaknya persaingan yang dapat seperti masih terlihat banyaknya pesaing yang meneyediakan jasa dengan harga yang lebih terjangkau dan murah bagi masyarakat medan, agar konsumen bengkel mulai berpikir ulang untuk setia pada Bengkel Sepeda Motor AHASS 2192dan tidak menggunakan jasa bengkel ini lagi.

Selain masalah kepercayaan, masalah kepuasan pelanggan juga terlihat jelas dimata pelanggan seperti masih terlihatnya pelanggan tidak senang dengan jasa yang digunakan disini, masih kurang ramahnya karyawan disini saat mereka menggunakan jasa ini apabila mereka bertanya karyawan disini seperti enggan untuk menjawab dan menjawab dengan apa adanya, serta hasil yang dilakukan bengkel ini kurang kualitasnya hanya beberapa bulan menggunakan jasa ini sudah harus ada lagi perbaikan lain yang muncul hal-hal seperti ini menyebabkan kepuasan pelanggan terganggu dan akan berakibat pada loyalitas pelanggan

\section{KAJIAN PUSTAKA}

\subsection{Kepercayaan}

Jurnal Insitusi Politeknik Ganesha Medan

Juripol, Volume 4 Nomor 1 Maret 2021 
Konsep kepercayaan pelanggan digunakan dalam penelitian ini sebagai landasan untuk memahami konsep dan indikator pengukuran kepercayaan pelanggan. Mancintosh and Lockskin (2009:489) mengemukakan definisi kepercayaan pelanggan : "define trust as one party's confidence in an exchangepartner's reliability and integrity”. Definisi kepercayaan pelanggan tersebut, menunjukan bahwa salah satu pihak percaya dan meyakini kehandalan dan integritas partner dalam pertukaran. Kemudian Deutsch (2008:68) trust is defined as theexpectation of the parties in a transaction and the risk associated. Kepercayaanadalah harapan yang ingin dicapai dari sekumpulan orang yang melakukan transaksi dengan mempertimbangkan risiko.

Berdasarkan beberapa definisi trust di atas, maka kepercayaan pelanggan yang dimaksud dalam penelitian ini adalah rasa percaya pelanggan pada perusahaan atau merek karena pelanggan tersebut yakin bahwa perusahaan/merek mampu memberikan nilai melebihi harapannya. Menurut Kennedy (2009:74) dalam mengembangkan konsep kepercayaan pelanggan pada perusahaan jasa menjadi dua variabel yaitu "kepercayaan pelanggan pada salesperson dan kepercayaan pelanggan pada perusahaan".

\subsection{Kepuasan}

Kepuasan pelanggan adalah keluaran dari proses kinerja sebuah perusahaan yang dirasakan oleh seorang konsumen, dimana hasilnya sesuai dengan harapan konsumen tersebut (Kotler, 2012:78). Irawan (2009:53) mengatakan "Kepuasan adalah hasil dari penilaian konsumen bahwa produk atau pelayanan telah memberikan tingkat kenikmatan dimana tingkat pemenuhan ini biasa lebih kurang atau lebih". Seperti dijelaskan dalam definisi diatas, kepuasan merupakan fungsi dari persepsi kesan atas kinerja dan harapan. Jika kinerja berada di bawah harapan, pelanggan akan kecewa. Bila kinerja memenuhi harapan, pelanggan akan puas dan bila kinerja melebihi harapan, pelanggan akan sangat puas, senang dan gembira.

Hawkins dan Lonney dikutip dalam Tjiptono (2010:101) atribut indikator pembentuk kepuasan terdiri dari :

a. Kesesuaian harapan .

b. Minat berkunjung kembali

c. Kesediaan merekomendasikan

\subsection{Loyalitas}

Menurut Tommy, dkk (2010:56) Loyalitas dapat dikatakan sebagai kesetiaan seseorang terhadap suatu hal yang bukan hanya berupa kesetiaan fisik 
semata, namun lebih pada kesetiaan non fisik seperti pikiran dan perhatian.

Loyalitas para karyawan dalam suatu organisasi itu mutlak diperlukan demi kesuksesan organisasi itu sendiri.Loyalitas adalah tentang presentase dari orang yang pernah membeli dalam kerengka waktu tertentu dan melakukan pembelian ulang sejak pembelian yang pertama.

Loyalitas merupakan besarnya konsumsi dan frekuensi pemakaian yang dilakukan oleh seorang konsumen terhadap suatu perusahaan.

Menurut hidayat (2009:103) loyalitas konsumen merupakan komitmen seorang konsumen terhadap suatu pasar berdasarkan sikap positif dan tercermin dalam pemebelian ulang secara konsisten. Indikator dari loyalitas konsumen adalah:

a. Trust, merupakan tanggapan kepercayaan konsumen terhadap pasar

b. Emotion Commitment, merupakan komitmen psikologi terhadap pasar

c. Switching cost, merupakan tanggapan konsumen tentang beban yang diterima ketika terjadi perubahan

\section{METODE PENELITIAN}

Jenis penelitian ini adalah asosiatif, menurut Sugiyono (2012:11), pendekatan asosiatif adalah pendekatan dengan menggunakan dua atau lebih variabel guna mengetahui hubungan atau pengaruh yang satu dengan yang lain. Penelitian ini dilakukan pada Bengkel Sepeda Motor AHASS 2192Medan yang beralamat jalan Panglima Denai No.124 C Medan Denai Kota Medan, Sumatra Utara. Populasi dalam penelitian ini adalah para pengunjung yang telah melewati masa gratis servis dan masih mempercayakan servis kendaraannya di Bengkel Sepeda Motor Ahass 2192 Medan yang berjumlah 150 orang konsumen yang sudah pernah memakai dan menggunakan jasa lebih dari 3 kali selama satu bulan penelitian. Jumlah sampel hasil perhitungan rumus slovin maka di ketahui jumlah sampel yang akan di teliti sebanyak 109 responden. Teknik pengumpulan data yang digunakan dalam penelitian ini adalah Pengamatan (observation) dan Daftar pertanyaan (questioner).Jenis dan sumber data dalam penelitian ini adalah data primer dan sekunder.

\section{DISCUSSION}

\subsection{Uji Validitas Dan Reliabilitas}

\section{a. Uji Validitas}

syarat minimum uji validitas untuk dianggap memenuhi syarat adalah kalau $r_{\mathrm{s}}$ tabel $=0,3$. Jadi, apabila korelasi antara butir pernyataan dengan skor total 
kurang dari 0,3 maka butir pernyataan dalam instrumen tersebut tidak valid.Berdasarkan data maka dapat disimpulkan bahwa semua butir penyataan tersebut valid dan layak untuk digunakan sebagai instrumen penelitian.

\section{b. Uji Reliabilitas}

Berikut ini sajikan nilai reliabilitas untuk ketiga variabel (Kepercayaan, Kepuasan Pelanggan, Loyalitas Pelanggan) yaitu:

Tabel 4.1

Hasil Uji Reliabilitas Variabel Y, X1, dan X2

\begin{tabular}{|l|c|c|}
\hline \multicolumn{1}{|c|}{ Variabel } & $\begin{array}{c}\text { Nilai } \\
\text { Reliabilitas }\end{array}$ & Status \\
\hline Kepercayaan (X1) & 0,898 & Reliabel \\
\hline Kepuasan Pelanggan (X2) & 0,954 & Reliabel \\
\hline Loyalitas Pelanggan (Y) & 0,945 & Reliabel \\
\hline
\end{tabular}

Sumber: Pengolahan SPSS (2020)

Berdasarkan tabel di atas, maka variabel kepercayaan, kepuasan pelanggan, loyalitas pelanggan di nyatakan reliabel. Hal ini dapat di lihat dari nilai variabel kepercayaan (X1) sebesar 0,898> 0,60 untuk variabel kepuasan pelanggan (X2) sebesar 0,954>0,60 dan variabel terikat loyalitas pelanggan (Y) sebesar $0,945>0,60$.

\subsection{Pengujian Asumsi Klasik}

\section{a. Uji Normalitas}

Hasil uji normalitas menggunakan histogram dapat dilihat pada gambar dibawah ini :

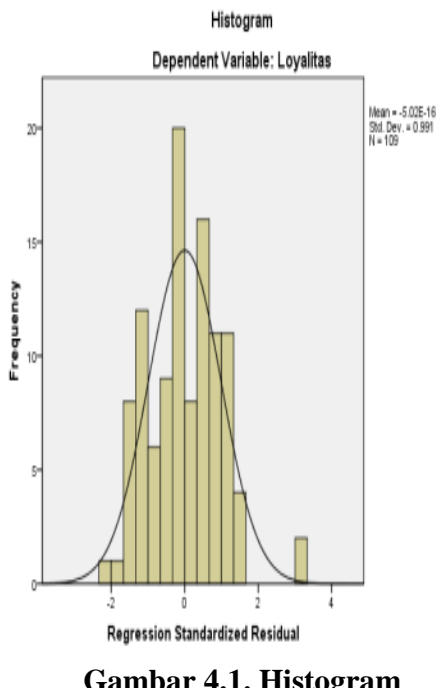

Jurnal Insitusi Politeknik Ganesha Medan 
Gambar histogram di atas menunjukkan bahwa data berdistribusi secara normal karena bentuk kurva memiliki kemiringan yang cenderung imbang dan kurva menyerupai lonceng. Maka dapat disimpulkan bahwa data tersebut normal.

Hasil uji normalitas menggunakan grafik normality probability plot dapat dilihat pada gambar dibawah ini

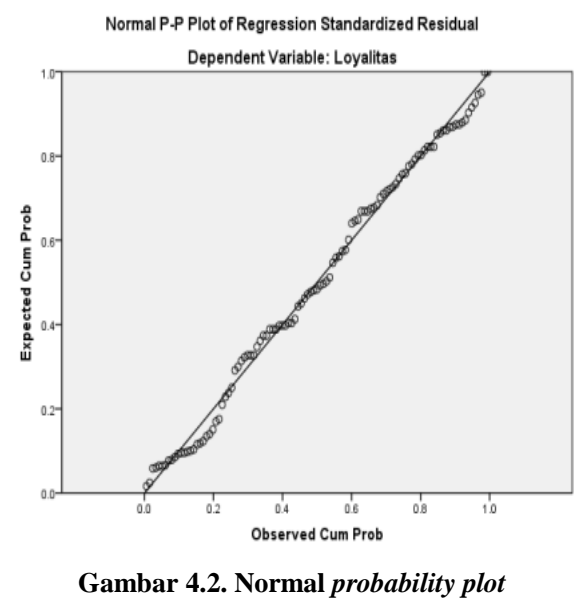

Gambar di atas menunjukkan bahwa probability plot memiliki pola distribusi normal karena pencaran data berada di sekitar garis diagonal dan mengikuti garis diagonal tersebut. Dengan demikian, dapat dikatakan bahwa penilitian ini memehuhi asumsi normalitas.

\section{b. Uji Multikolinieritas}

Uji mulitikolinieritas bertujuan untuk menguji apakah pada model regresi ditemukan adanya korelasi antar variabel independen.

Hasil pengujian multikolinieritas data dalam penelitian ini menggunakan alat bantu SPSS, hasilnya dapat dilihat pada Tabel berikut :

Tabel 4.3

Uji Multikolineritas

\begin{tabular}{|ll|r|c|}
\hline \multirow{2}{*}{ Model } & \multicolumn{2}{|c|}{ Collinearity Statistics } \\
\cline { 3 - 4 } & & Tolerance & \multicolumn{1}{c|}{ VIF } \\
\hline 1 & (Constant) & & \\
& Kepercayaan & .782 & 1.279 \\
& Kepuasan & .782 & 1.279 \\
\hline
\end{tabular}

Hasil analisis menunjukkan bahwa nilai VIF untuk variabel independen dibawah nilai 5 sebesar 1.279 dan nilai tolerance dibawah nilai 1 sebesar 0.782 yang berarti tidak terjadi multikolinearitas sehingga model tersebut reliable sebagai dasar analisis.

\section{c. Uji Heteroskedastisitas}


Pengujian ini bertujuan untuk melihat apakah dalam model regresi terjadi ketidaksamaan variabel dari residual satu pengamatan ke pengamatan lain.Hasil dari uji heterokedastisitas dapat dilihat pada grafik scatterplot berikut ini :

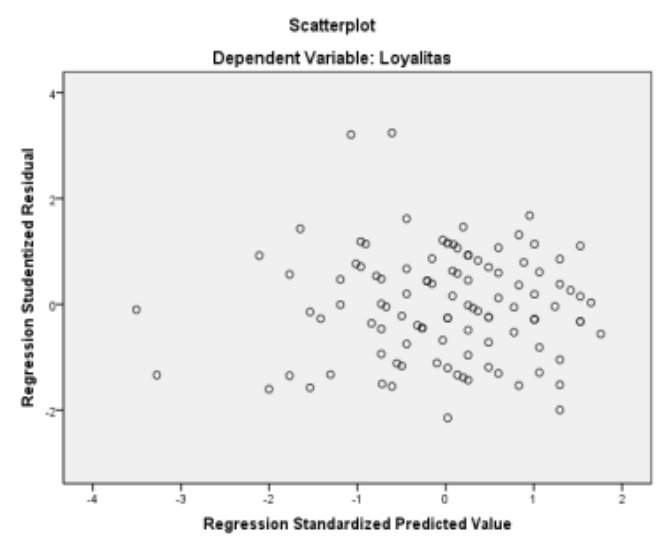

Gambar 4.4.grafik scatterplot

Gambar di atas grafik scatterplot terlihat bahwa titik-titik menyebar secara acak dengan tidak adanya pola yang jelas serta tersebar baik di atas maupun dibawah angka 0 pada sumbu $\mathrm{Y}$. Hal tersebut menunjukkan bahwa tidak terjadi heterokedastisitas, sehingga model ini layak dipakai untuk memprediksi berdasarkan masukan variabel independen.

\section{KESIMPULAN}

Dari hasil pemaparan dan pembahasan data di atas maka kesimpulan darihasil penelitian adalah :

1. Berdasarkan hasil uji hipotesis (uji t) bahwa variabel kepercayaan, dimana taraf singnifikan $\alpha 5 \%$ nilai thitung $4.985>\mathrm{t}_{\text {table }} 1.658$ artinya positif dan nilai $p$ value pada kolom sig $0.000<0.05$ artinya signifikan. Hal ini menjelaskan bahwa kepercayaan berpengaruh positif dan signifikan terhadap loyalitas pelanggan pada Bengkel Sepeda Motor Ahass 2192Medan

2. Berdasarkan hasil uji hipotesis (uji t) bahwa variabel kepuasan, dimana nilai table pada $\alpha 5 \%$ yakni 1.658 artinya positif. Dimana taraf singnifikan $\alpha 5 \%$ nilai thitung $4.840>t_{\text {table }} 1.658$ dan nilai $p$-value pada kolom sig $0.000<0.05$ artinya signifikan. Hal ini menjelaskan bahwa kepuasan dapat berpengaruh positif dan signifikan terhadap loyalitas pelanggan pada Bengkel Sepeda Motor Ahass 2192Medan.

3. Berdasarkan hasil uji $\mathrm{F}$ secara simultan Nilai $\mathrm{F}_{\text {hitung }}>\mathrm{F}_{\text {tabel }}$ diperoleh 45.289 $>3.08$ artinya positif. Sementara nilai p-value diperoleh pada kolom sig $0.000<$ 0.05 artinya signifikan. Dengan demikian dapat disimpulkan bahwa kepercayaan dan kepuasan secara simultan dapat berpengaruh positif dan signifikan terhadap 
loyalitas pelanggan pada Bengkel Sepeda Motor Ahass 2192Medan.Berdasarkan perhitungan koefisien determinasi, dapat dilihat nilai Adjusted $\mathrm{R}$ Square yang diperoleh sebesar 0,451. Angka tersebut menunjukkan bahwa sebesar 45,1\%. loyalitas(variabel terikat) dapat dijelaskan oleh variabel faktor kepercayaan dan kepercayaan Sisanya sebesar 54,9\% dipengaruhi oleh faktor-faktor lain yang tidak dijelaskan dalam penelitian ini.

\section{REFERENCES}

Ghozali, I. (2011). Aplikasi Analisis Multivariate Dengan Program SPSS. Semarang: Badan Penerbit Universitas Diponegoro.

Griffin, R. W. (2013). Perilaku Organisasi. Jakarta: Salemba Empat.

Hasan, A. (2013). Marketing dan Kasus-Kasus Pilihan. Yogyakarta: CAPS (Center For Academic Publishing Service).

Irawan, H. (2009).10 Prinsip Keouasan Pelanggan.Jakarta: Elex Media Komputindo.

Jugiyanto. (2010). Analisis dan Desain Sistem Informasi, Edisi IV. Yogyakarta: Andi Offset.

Kotler, \& Keller. (2012). Manajemen Pemasaran. Edisi 12. Jakarta: Erlangga.

Lupiyoadi, R. (2013). Manajemen Pemasaran Jasa. Jakarta: Salemba Empat.

Sangadji, E. M., \& Sopiah. (2013). Perilaku Konsumen: Pendekatan Praktis Disertai. Himpunan Jurnal Penelitian. Yogyakarta: Penerbit Andi .

Sheth, J. N. (2010). The Theory of Buyer Behavior. New York: John Wiley.

Sugiyono. (2012). Metode Penelitian Kuantitatif Kualitatif dan R \& B. Bandung: Alfabeta.

Sukardi. (2011). Metode Penelitian Pendidikan Kompetensi dan Praktiknya. Yogyakarta: Bumi Aksara.

Sumardi, U., \& dkk. (2010). Pemasaran Strategik (Prespektif Value-Based Marketing \& Pengukuran Kinerja). Bogor: IPB Pres.

Tjiptono, F. (2011). Service Management Mewujudkan Layanan Prima. Edisi 2. Yogyakarta: Andi.

Harumi, S. D. (2015). Pengaruh Kepercayaan dan Kepuasan Pelanggan Terhadap Loyalitas Pelanggan di Perusahaan Seiko Laundry Medan. Jurnal Ekonomi Dan Bisnis. 
Kanaidi. (Desember 2010). Pengaruh Customer Value dan Corporate Image Terhadap Loyalitas Pengguna Jasa Paket Pos di Wilayah Pos Bandung Raya. "COMPETITIVE". Majalah Ilmiah, Vol.6 No.2 , ISSN : 0216 : 2539.

Kennedy. (2009). Does patient satisfaction affect patient loyalty? International Journal of Health Care Quality Assurance. Vol.24 No.4 , 266-273.

Lua, G. T., \& Lee, S. H. (2009). Consumers' Trust in a Brand and the Link to Brand Loyalty.Journal of Market-Focused Management, 321-370.

Macintosh, G., \& Lockshin, L. S. (2007). Retail relationships and store loyalty: a multilevel perspective.International Journal of Research in Marketing. Vol 5 .

Nidyatantri, N. M., \& dkk. (2016). Pengaruh Kepuasan dan Kepercayaan terhadap Loyalitas Konsumen Kedelai Jepang Edamame Pendekatan Structural Equation Modeling. Jurnal Ekonomi Dan Bisnis .

Suwardi. (2011). Menuju Kepuasan Pelanggan Melalui Penciptakan Kualitas Pelayanan. Jurnal Ragam, Jurnal Pengembangan Humaniora Vol. II, No.1. Politeknik Negeri Semarang .

Winahyuningsih, P. (2010). Pengaruh Kepercayaan Dan Kualitas Pelayanan Terhadap Kepuasan Konsumen Pada Hotel Griptha Kudus. Jurnal Sosial dan Budaya, Vol.3, No.2 , 3-4. 